\title{
Distance Diffusion of Home Bias for Crowdfunding Campaigns between Categories: Insights from Data Analytics
}

\author{
Lihuan Guo ${ }^{1,2}$, Dongqiang Guo ${ }^{1}$, Wei Wang ${ }^{1}$, Hongwei Wang ${ }^{3 \text { (i) }}$ and Yenchun Jim Wu ${ }^{4, *}$ (D) \\ 1 College of Business Administration, Huaqiao University, Quanzhou 362021, China; guo@qztc.edu.cn (L.G.); \\ gdq@hqu.edu.cn (D.G); wwang@hqu.edu.cn (W.W.) \\ 2 College of Chen Shouren Business and Information, Quanzhou Normal University, Quanzhou 362000, China \\ 3 School of Economics and Management, Tongji University, Shanghai 200092, China; hwwang@tongji.edu.cn \\ 4 Graduate Institute of Global Business and Strategy, National Taiwan Normal University, \\ Taipei 10645, Taiwan \\ * Correspondence: wuyenchun@gmail.com; Tel.: +886-2-7734-3996
}

Received: 25 March 2018; Accepted: 18 April 2018; Published: 19 April 2018

check for updates

\begin{abstract}
As the information communication and investment of crowdfunding campaigns are usually accomplished online, online crowdfunding theoretically breaks the limitation of space. However, investors' behaviors still show significant home bias; furthermore, from a dynamic view, the changes in home bias during the funding duration reflect the investment preference. This paper studies the dynamics of home bias in crowdfunding investment as well as the distance diffusion of home bias in the crowdfunding market through data mining and econometric models. The distance between investors and founders gradually increases from $3605 \mathrm{~km}$ to $4229 \mathrm{~km}$ as the funding progresses, and home bias shows different diffusion patterns between categories. For most of the campaigns, the distance between backers and founders of the successful campaigns is always greater than that of the failed ones; thus, the distance diffusion impacts the pledge results. However, the study also finds that for some categories, home bias does not play a positive role in investment or that it even shows negative impacts, among which food and technology are two extreme categories. The study provides a theoretical basis from the perspective of user behavior to analyze online investment and to improve the promotion of crowdfunding campaigns.
\end{abstract}

Keywords: entrepreneurship; crowdfunding; home bias; distance diffusion; pledge results; Kickstarter

\section{Introduction}

Taking the online crowdfunding market as an example, project exhibition and investment are conducted over the Internet without any geographical restrictions; it should therefore not show any obvious home bias (also known as the geographic effect or geographical preference). However, our preliminary study shows that investments in crowdfunding projects present significant home bias. It is of great significance to promote the development of Internet finance through an in-depth analysis of investor behavior and an understanding of users' investment preferences, especially in a dynamic way.

In the online peer-to-peer (P2P) lending market, investors' behaviors show a significant home bias trend [1]. That is, investors prefer to support projects launched by founders from the same nation, same province (state), or same city [2]. In other words, investors are inclined to support projects near the location where they live, when the distance between the founders and the backers is small. However, in the literatures we could find, few studies focused on the distance diffusion of home bias in a dynamic way in the field of crowdfunding. Specifically, the distance diffusion of home bias associated 
with dynamic behavior patterns in the Internet financial market may exist and influence pledge results. According to the theory of social networking [3], a reasonable but unverified assumption is that early investors are closer to the founders, and that the distance increases gradually and spreads to a wide geographical scope as time goes on. However, in the field of crowdfunding we find no literature to distinguish the differences between home bias and social relationships.

Crowdfunding can be classified into many models, among which the reward-based model has been the fastest growing one in recent years [4]. Instead of rewarding the backers with cash or equities, the reward-based model pays the backers in promise types involving products or virtual items (such as the artist's signed photos, films, TV shows, t-shirts, and pre-sale products) [5]. Due to the unforeseen nature of the investment, the rewards promised by the founders are the main motivation for many investors to participate in the campaigns [6]. Reward-based crowdfunding has been a hot spot in recent years, and it gave birth to the world's largest reward-based crowdfunding platform called Kickstarter. In addition to the rewards promised by founders, investors' home bias also impacts the investors' investment intention in the reward-based crowdfunding campaigns. As the investment is a continuous process, investors can participate in the campaign before its completion, which involves dynamic home bias, that is, distance diffusion. Dynamic home bias can characterize the investor behavior patterns in a more profound way than a static process. It is therefore a promising direction for studying the home bias of investors from a dynamic perspective.

As for real data, Figure 1 shows the average distance between investors and founders in different phases of funding for 17,024,837 investments in 136,234 crowdfunding projects from Kickstarter. The distance between investors and founders is calculated in kilometers. The duration of the investment is divided evenly into 20 phases. As seen in Figure 1, the average distance between the two sides is $3329 \mathrm{~km}$ in the first phase. As funding progresses, the distance between the two sides spreads gradually and reaches $3956 \mathrm{~km}$ in the 20th phase. Thus, in the face of this phenomenon, we are dedicated to exploiting the distance diffusion and the impact of crowdfunding campaigns on financial performance.

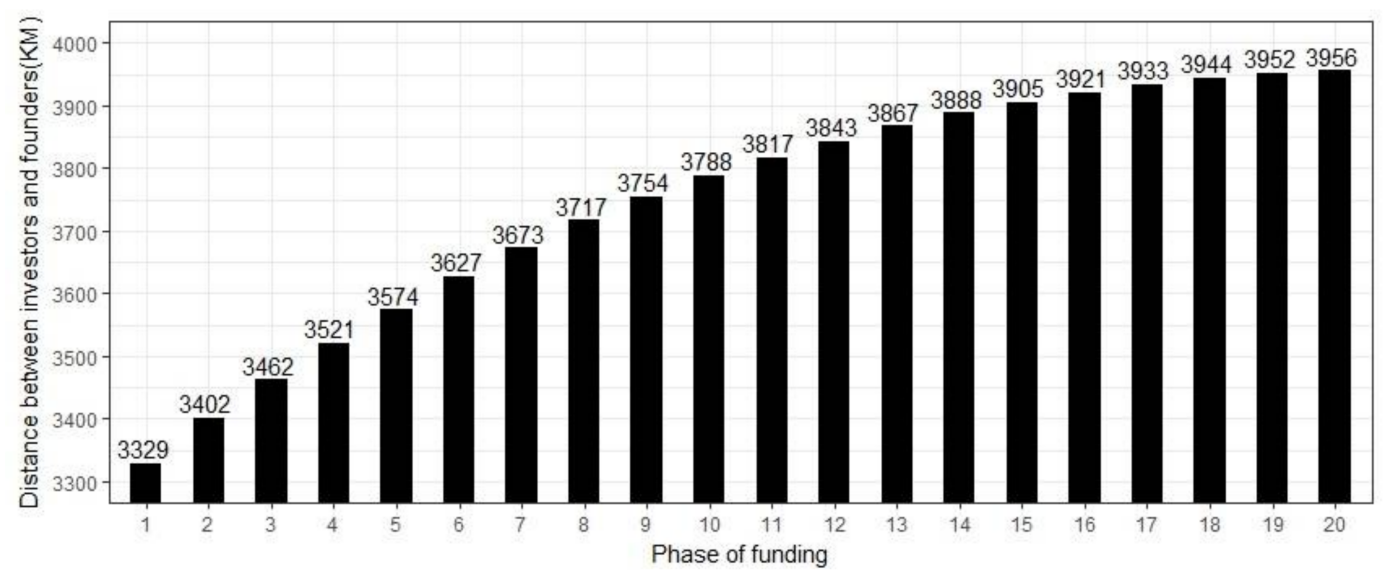

Figure 1. The average distance between investors and founders in different phases of funding.

The extensive statistical results in Figure 1 do not indicate the differences in the distance diffusion under project categories or the impact of distance diffusion on pledge results. While investors prefer to invest in campaigns with a relatively short distance, there are however theoretical differences between home bias and the distance diffusion itself. Home bias statically describes the investment habits of individual investors, while distance diffusion describes the dynamic investment pattern for the majority of investors at the level of groups. Therefore, this paper is devoted to resolving the questions of how distance is spread out in crowdfunding investment, and whether there are any differences between categories at the national, state, city, and distance levels. Additionally, how do distance diffusion and home bias affect the financial performance of the projects? 
We employed data mining and econometrics models to carry out an empirical analysis on the data from Kickstarter and to study the home bias and the distance diffusion of investors at the national, state, city, and distance levels. This study has theoretical and practical values for guiding investing and financing practices.

\section{Literature Review}

\subsection{Studies on Crowdfunding}

Crowdfunding is the practice of funding a project or venture by raising monetary contributions from a large number of people. It is often performed via Internet-mediated registries, but the concept can also be executed through mail-order subscriptions or other channels [7]. In reward-based crowdfunding, capital-giving motivation is influenced by social relationships [3]. Some backers do not care about the physical return; instead, they are more concerned with a psychological return [8]. Those investors are often the founders' friends or family members. Some studies focus on the assessment of project qualities $[9,10]$, showing that the success rate of crowdfunding is affected by external quality signals [11] including preparation, the attitude of other investors, the personality of the founders, credit rating, and social relationships [12,13].

Many researchers suggest that family and friends are the main source of money during the early stages of funding [14]; reciprocal giving is, for instance, significant in reward-based crowdfunding [15]. The importance of investment from friends and family was verified by data from SellaBand.com, which is consistent with other similar studies [16]. Successful projects can gain support from the founders' friends in social networks in the early funding phases, which is reflected in the number of Facebook followers or Twitter fans [17]. The success rate of crowdfunding was significantly and positively correlated with the number of followers on Facebook [18]. Social relationships show the quality of the creditworthiness of the founders; specifically, social networking increases the probability of successful funding while also lowering the interest rates and default rates on borrowings [19]. Social networking shows astonishing economic potential and has a positive impact on free financial markets and decentralized e-market design [20].

\subsection{Studies on Home Bias}

A study shows that lenders in the P2P lending market often ignore business characteristics and focus on personal characteristics instead, such as the gender of the borrowers or their location [21,22]. Although there exist some studies and explanations of gender bias, studying home bias is much more complicated. Home bias has already been studied in several areas, typically in business, economics, and finance [23-25]. Throughout current research, many studies mainly adopt offline data to confirm that home bias has a wide range of effects, in market transactions and venture capital for instance. Home bias affects many aspects of user behavior, including economics, geopolitics, culture, and consumer habits. Users tend to invest in projects that are culturally similar to their respective home countries [26].

Considering research and development (R\&D) enterprises as an example, this can be completed in any geographical area, and the locations scattered in different addresses can make full use of the advantages of talent and culture from different areas. For example, Microsoft set up the Asian Institute. However, a significant proportion of R\&D companies show a bias toward local resources [27]. Researchers have studied the impact of FDI on the flow of funds and on the trade integration of the European Union (EU), which does not adopt indicators such as tariffs or nontariff barriers but mainly adopts trade activities with a home bias. Using data from 1995 to 2009, they found that a country's trade integration and FDI activities were significantly positively correlated. However, the EU may be a special case because it is not possible to strictly distinguish between horizontal and vertical foreign direct investment [28]. 
A study of the Eurozone's debt crisis finds that home bias highlights the impact on domestic shocks and aggravates the debt crisis. The results support the prediction of the theoretical model; that is, that the consequences of the sovereign debt crisis depend on initial domestic instability and the influence of increasing home bias. They also suggest that increasing home bias reflects worsening fiscal conditions under sovereign debt pressures but could also reduce the possibility of default because local companies prefer local resources [29]. Since asset markets are incomplete, the results also show a significant home bias for transnational transactions in the financial market. Investors often trade a lot in foreign assets and hold so little of them in their portfolios, which increases the riskiness of foreign assets and facilitates risk-sharing across countries [30].

However, a study shows that the spillover effects of cultural and economic distances are more significant than the effects of geometric distance alone. Investors' familiarity with Asian countries seems to influence the fact that there is a similar extent of home bias across Asian financial markets, while this is not the case in developed countries [31]. In other words, different financial markets hold different attitudes toward economic distance and home bias.

\subsection{Distance Diffusion and Interpretation}

Existing studies on home bias have often focused on offline scenarios, and some researchers shifted their focus to online transactions with the rise of e-commerce. The earliest research on online trading notes that trading on eBay presents home bias. Researchers explain that some deals on eBay involve the sales of tickets, for a concert in New York for instance, in which merchants are likely from New York and consumers often live near New York as well. Thus, these transactions related to entity trading present typical geographic consistency. Another possible explanation is that distance proximity is beneficial for buyers and sellers as they can enter into a face-to-face contract [32].

Many researchers explain home bias from the perspective of the trading cost. For example, the current $R \& D$ of multinational enterprises is becoming common, and the preference for local resources is increasing with the scale effect, the scope economy, the coordination cost of international $R \& D$, and the innovation system in the country in which the enterprises are located. Technology-leading is also associated with home bias and is often reflected in the strong intellectual property protection provided by the home country, along with potential foreign knowledge dissipation [27]. As measured by the speed of patent citations, knowledge spreads more slowly over international boundaries than within them, which is also known as home bias of knowledge spillovers [33].

Some explanation of home bias is focused on psychology [34]. Studies note that cultural and patriotic sentiments affect home bias, which affects bond portfolio investments. Most existing studies note that cultural and patriotic sentiments have a substantial impact on home bias in equity. The influence is often estimated from the following two perspectives: domestic preferences (overinvestment in domestic debt) and foreign preferences (underinvestment of the bonds issued by different countries). As a result of home bias, there is strong evidence that patriotism hampers foreign investment while overbilling domestic bonds. Due to home bias, investors from countries with higher uncertainties invest less in foreign bond markets [35]. Moreover, the trend of home bias for such investments has become more pronounced in recent years [36].

Some studies use cultural distance to explain the phenomenon of distance diffusion. Portfolios from culturally distant countries invest less abroad and under-weigh culturally distant target markets [37]. In the art auction market, the distance diffusion of home bias is especially obvious. With other conditions being the same, artwork for auctions tends to bid at a higher price in the artist's hometown, and the auction price declines with an increased distance from the city where the artist resides [38]. This indicates that the increase in distance leads bidders to lower the psychological price of the art; thus, distance diffusion causes bidders to lower the valuation of artwork. As funding is a dynamic process, the time factor would also impact the pledge [39]. 


\section{Research Gap and Research Questions}

\subsection{Research Gaps}

The existence of home bias in offline transactions as well as in e-commerce has been widely confirmed. In a similar study, researchers analyzed the home bias in P2P lending markets [1]. However, in new business models such as crowdfunding, we could find no systemic research on the home bias of investment behavior in the literature. Therefore, theoretical support as well as managerial insights for this new Internet financial model cannot be provided. Most existing research on crowdfunding is related to the impact of social relationships on pledge results or to investment factors analyses; thus, there is a lack of in-depth analysis on home bias. We can understand the investment preferences of investors and provide a basis for research and application on crowdfunding with an in-depth analysis of investment home bias.

Using the reward-based crowdfunding model as an example, founders often promise the investors a return; however, in a virtual platform, transactions and agreements among the founders, investors, and crowdfunding platforms are not signed face-to-face. There is therefore rarely face-to-face accountability, even in the case of default. In addition, because of the nature of crowdfunding, each investor invests only a small portion of money, as required by the project. For investors, there is therefore little incentive to enter into a direct agreement with founders and regulate the campaigns. In this context, home bias should not play a role in crowdfunding investment. However, almost no studies attempt to answer this question and the mechanism of home bias has not yet been discussed in the crowdfunding field, and neither has the distance diffusion of home bias.

Furthermore, most existing related research considers home bias to be a static variable and ignores the dynamic aspect of its distance diffusion. We can obtain the home bias spread by considering the time factor in the model. From the initial stage to the end of financing, there is a gap in the question of how the distance changes between the founders and backers, as well as in the question of how the distance diffusion impacts the success rate of the crowdfunding projects. We cannot find similar research on crowdfunding that combines both home bias and distance diffusion; therefore, there is a theoretical gap in crowdfunding practice.

\subsection{Research Question Definition}

Existing studies are almost solely focused on static behavior analysis; they do not consider the time factor in home bias and thus do not incorporate either distance diffusion analysis in the online financial market or the impact of distance diffusion on the pledge results of crowdfunding campaigns. Due to differences in the evaluation criteria for different categories, distance diffusion of home bias should present differences among categories correspondingly. Analyzing the differences is helpful to understand investment standards among investors in different categories as well as helping recognize behavior patterns that provide a new channel for mining the value of user behavior for online finance.

According to gaps in existing research and applications, we propose the following research questions.

(1) How is the distance of home bias spread out for investors? Are there differences in the distance diffusion between categories? What are the differences if the answer to the previous question is yes? Does distance diffusion of home bias show user dependence, that is, is it caused by some extreme users, or is it the common behavior of most investors?

(2) What is the difference between levels? Namely, what are the differences in the distance diffusion of home bias at the national, state, city, and distance levels? What is the impact of distance diffusion on the pledge results of the campaigns, that is, if the investors are dispersed in a wide geographical location in the early phase of funding, is this favorable or unfavorable to the success of the project? 


\section{Materials and Methods}

\subsection{Data Summary}

Experimental data came from Kickstarter, the world's largest reward-based crowdfunding platform for creative ideas. Kickstarter was launched in 2009, with a current Alexa ranking of 544th. Anonymity is allowed when accessing Kickstarter for free, and Kickstarter keeps track of information on all projects including both successful and failed campaigns, which provides a channel to extract the data.

Table 1 shows the category statistics for the sample. Kickstarter's campaigns fall into 15 categories; overall, film \& video as well as music projects are major parts of the sample. In terms of the success rate, dance is the highest (74\%) among all categories, while fashion is the lowest (35\%). The average success ratio is approximately $48.49 \%$, which coincides with prior data collection [5].

Table 1. The category statistics for the sample.

\begin{tabular}{cccccccc}
\hline Category & Number & Percentage & Avg. Goal & Avg. Backer & Avg. Pledged & Progress & Success Ratio \\
\hline Art & 10,965 & $8.05 \%$ & $20,466.67$ & 45 & 3533.75 & $204.48 \%$ & $53.75 \%$ \\
Comics & 3995 & $2.93 \%$ & 8583.20 & 93 & 7337.16 & $287.36 \%$ & $52.59 \%$ \\
Crafts & 1170 & $0.86 \%$ & 5316.83 & 39 & 2626.00 & $152.02 \%$ & $44.96 \%$ \\
Dance & 1854 & $1.36 \%$ & 5623.66 & 49 & 3678.75 & $110.00 \%$ & $73.84 \%$ \\
Design & 7900 & $5.80 \%$ & $24,948.62$ & 113 & $23,135.55$ & $203.55 \%$ & $41.19 \%$ \\
Fashion & 5462 & $4.01 \%$ & $12,861.86$ & 54 & 6802.46 & $211.50 \%$ & $34.77 \%$ \\
Film \& Video & 31,979 & $23.47 \%$ & $32,336.32$ & 56 & 6962.71 & $150.45 \%$ & $45.80 \%$ \\
Food & 6137 & $4.50 \%$ & $17,945.84$ & 75 & 7827.61 & $176.45 \%$ & $42.11 \%$ \\
Games & 9926 & $7.29 \%$ & $37,809.45$ & 115 & $25,296.71$ & $1041.18 \%$ & $38.71 \%$ \\
Journalism & 879 & $0.65 \%$ & $37,660.54$ & 51 & 4674.01 & $63.25 \%$ & $42.43 \%$ \\
Music & 26,855 & $19.71 \%$ & 9044.09 & 57 & 4318.43 & $121.96 \%$ & $61.75 \%$ \\
Photography & 4037 & $2.96 \%$ & $10,405.18$ & 45 & 3475.19 & $67.78 \%$ & $41.52 \%$ \\
Publishing & 14,581 & $10.70 \%$ & 9473.44 & 49 & 3524.34 & $241.95 \%$ & $38.17 \%$ \\
Technology & 4645 & $3.41 \%$ & $58,519.93$ & 104 & $37,504.03$ & $168.95 \%$ & $37.03 \%$ \\
Theater & 5849 & $4.29 \%$ & $11,207.05$ & 51 & 4343.29 & $88.31 \%$ & $68.85 \%$ \\
Sum & 136,234 & & $20,961.79$ & & 8843.46 & $48.49 \%$ \\
\hline
\end{tabular}

For pledge goals, technology is the highest with an average of $\$ 58,520$, while craft is the lowest with $\$ 5316$ on average. Accordingly, the highest pledged category is technology, with $\$ 37,504$, while the lowest is crafts with $\$ 2626$. The average duration ranges from 33 to 37 days. In terms of the number of backers, games attract the largest number of backers, while art is the lowest on average. This indicates that cyber-users are more concerned with games than with art; however, art ranks much higher than games in terms of the success rate (45\% vs. 39\%).

\subsection{Measurements and Distance Calculation}

As the location details for the projects and the investors are provided for the campaigns and backers, following this, we needed to convert the geographical location into latitude and longitude, which was a complicated and time-consuming job.

In the campaign's homepage, we can obtain the address, such as "San Diego, CA," before calling the Google Maps API (Geocoding API, https:/ / developers.google.com/maps/documentation/ geocoding/) to retrieve the latitude and longitude of the address. For example, the latitude and longitude of "San Diego, CA" are 32.7157380 and -117.1610840, respectively. After obtaining the latitude and longitude of the location, the earth sphere distance calculation approach was adopted to calculate the distance between any two points. In the calculation, the distance between investors and founders was calculated by a straight line rather than pavement distance; this should not impact the results because the distance between cities is usually closer than that between countries.

Equations (1) and (2) show the distance calculation approach, in which the latitude and longitude of the first point $A$ is $(\operatorname{Lng} A, \operatorname{Lat} A)$ and the latitude and longitude of the second point $B$ is $(\operatorname{Lng} B, \operatorname{Lat} B)$ : 


$$
\begin{gathered}
c=\sin (\text { Lat } A)^{*} \sin (\text { Lat } B)^{*} \cos (\operatorname{Lon} A-\operatorname{Lon} B)+\cos (\text { Lat } A)^{*} \cos (\text { Lat } B) \\
\text { Distance }=\operatorname{Arccos}(c)^{*} R^{*} P i / 180
\end{gathered}
$$

In Equations (1) and (2), Distance() is the distance between $A$ and $B, \operatorname{Arccos}()$ represents the arccosine function, $R$ is the radius of the Earth, and the value of $R$ is set to $6371.004 \mathrm{~km}$. Accordingly, the distances are represented in $\mathrm{km}$.

\subsection{Methodology}

The data we collected stems from projects all over the world. However, being a US-based website, the vast majority of founders and investors are from the United States. Approximately $87.08 \%$ of projects are launched by US founders; these projects have significantly higher success rates than those from other countries, with $48.83 \%$ and $42.45 \%$ respectively. As a matter of fact, approximately $54.4 \%$ of the traffic comes from US, according to Alexa data. Therefore, to a certain extent, being a website from the US, investors will be more inclined to fund US projects.

However, it is not fair to consider only home bias at the national level. On the Kickstarter page, both investors and founders can choose to display their detail location, which provides a proxy to calculate the distance between founders and backers. Home bias involves different levels, including national markets, regional markets, and micro markets $[1,40]$. We therefore try to measure home bias and influences at different levels: (1) National-level home bias, which means the ratio of the investors who invest in projects from the same country. Investors prefer to invest in projects from their home country if national-level home bias exists and plays a role; (2) State-level home bias: similar to national-level home bias, state-level home bias indicates the ratio of backers from the same state (province) as the founders. State-level home bias measures the investor's geographical preference at a finer level; (3) City-level home bias, which presents the ratio of backers from the same city as founders; (4) Distance, for which in this study we adopted kilometers to measure the distance between backers and founders. Distance measures the investor's home bias in a way that can be quantified and compared and shows the distance diffusion for crowdfunding investors.

We estimated the financial impact of distance diffusion of home bias on pledge results and created a model as shown in Equation (3):

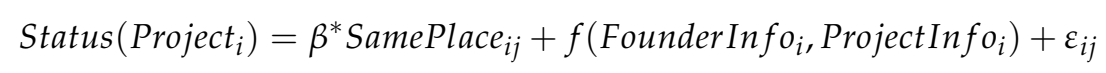

where Status $\left(\right.$ Project $\left._{i}\right)$ means the pledge results, as Kickstarter adopts the "All-or-Nothing" mode, and the status of a project means the campaign has been funded successfully or has failed. The reason this model works is that there will be significantly more local investors than remote backers if home bias works for the cross-sectional data; therefore, projects involving more local investors will be more likely to succeed. In other words, pledge results are significantly impacted by local investors; that is, $\beta$ should be significantly and positively correlated. Since the status of the project in Equation (3) has only two statuses, 1 for success and 0 for failure, a logit model is adopted to estimate the effect.

To explain the coefficients of the econometric model in detail, marginal effects are adopted. As the model we employ is the logit model, where the dependent variable is a dummy, the marginal effects refer to the probability of a dependent variable from 0 to 1 for a $1 \%$ change in independent variables, and a logit model can be presented as Equation (4):

$$
p=\operatorname{Pr}[y=1 \mid x, z]=\frac{\exp (\alpha+\beta \cdot \ln x+\gamma z)}{1+\exp (\alpha+\beta \cdot \ln x+\gamma z)}
$$

After some tedious calculus and simplification, the partial of that with respect to $x$ becomes a simplified formula, as shown in Equation (5): 


$$
\frac{\Delta p}{100 \cdot \frac{\Delta x}{x}}=\frac{\beta \cdot p \cdot(1-p)}{100}
$$

The equation is in a semi-elasticity formation and can be interpreted as the change in probability of success funding for a $1 \%$ change in $x$. The greater the marginal effects, the greater the impact on funding results once the value of the variable is changed to the same degree.

Some crowdfunding projects attract very few investors, and these campaigns with small numbers of investors make it difficult to estimate the impact of distance diffusion. Therefore, in the financial impact of home bias testing model, we only employed the projects that are supported by more than 200 backers. The reasons for choosing these projects include the following: (1) these projects often maintain a stable trend and demonstrate the distance diffusion of home bias more obviously; (2) these projects reflect the patterns and trends of investments comprehensively and enduringly; and (3) these projects are able to demonstrate the diffusion process of home bias, which helps to evaluate the effect of distance diffusion on crowdfunding markets. The appendix shows the data summary of the campaigns with 200 plus investors.

\section{Results}

\subsection{Difference between Distance Diffusion of Home Bias}

The duration is uniformly divided into 20 phases, and the differences between successful projects and failed campaigns in the distance diffusion are compared. Figure 2 shows the distance diffusion at national-level, state-level, and city-level home biases in the pool data. We can see that national-level home bias is the most intense, followed by state-level, and finally city-level. The home bias declines over time, which is confirmed at all levels.

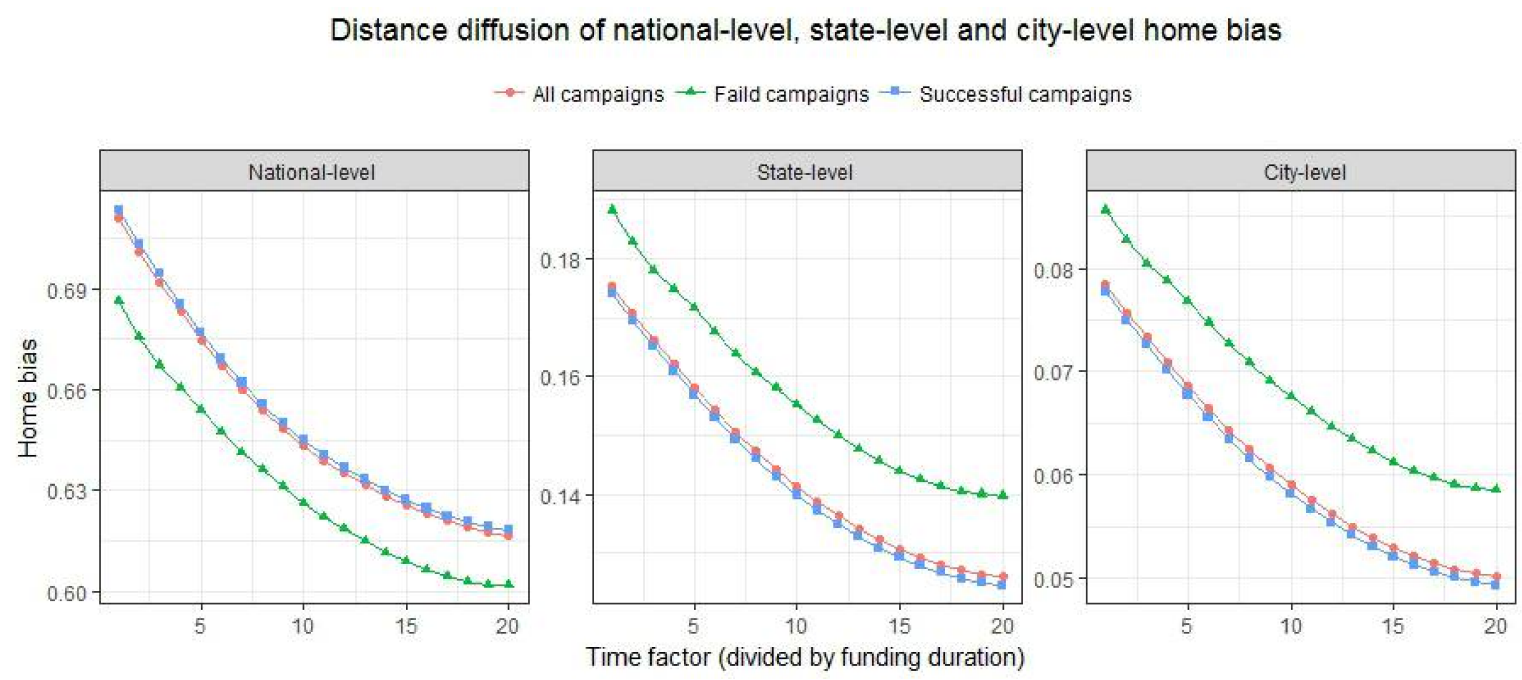

Figure 2. Distance diffusion at national-level, state-level, and city-level home biases.

National-level home bias refers to the ratio of investors and founders from the same country. The larger the ratio, the more investors like investing in the campaigns from their own country, which means that national-level home bias is more significant. Overall, the investment on Kickstarter shows significant national-level home bias. Successful projects show different trends from failed ones, i.e., national-level home bias for successful projects is weaker than that for failed projects. That is, successful projects can gain more support from foreign investors than from local backers.

Figure 3 shows the home bias diffusion between categories. Different categories show significant differences. For example, the home bias curve for technology projects is very steep, while the home bias curve for theater projects is very flat; this means that technology projects have gained more money 
from domestic investors, and as the financing progresses, investors will quickly expand into the global scope. In fact, at the 20th phase, the national-level home bias for technology projects is 0.54 ; namely, approximately $46 \%$ of investors come from different nationalities than the founders. In contrast, there is almost no change for the theater between phases, with a national level of 0.84 in the 1st phase and of 0.86 in the 20th phase, which indicates that the vast majority of theater investors come from the same country as the founders.

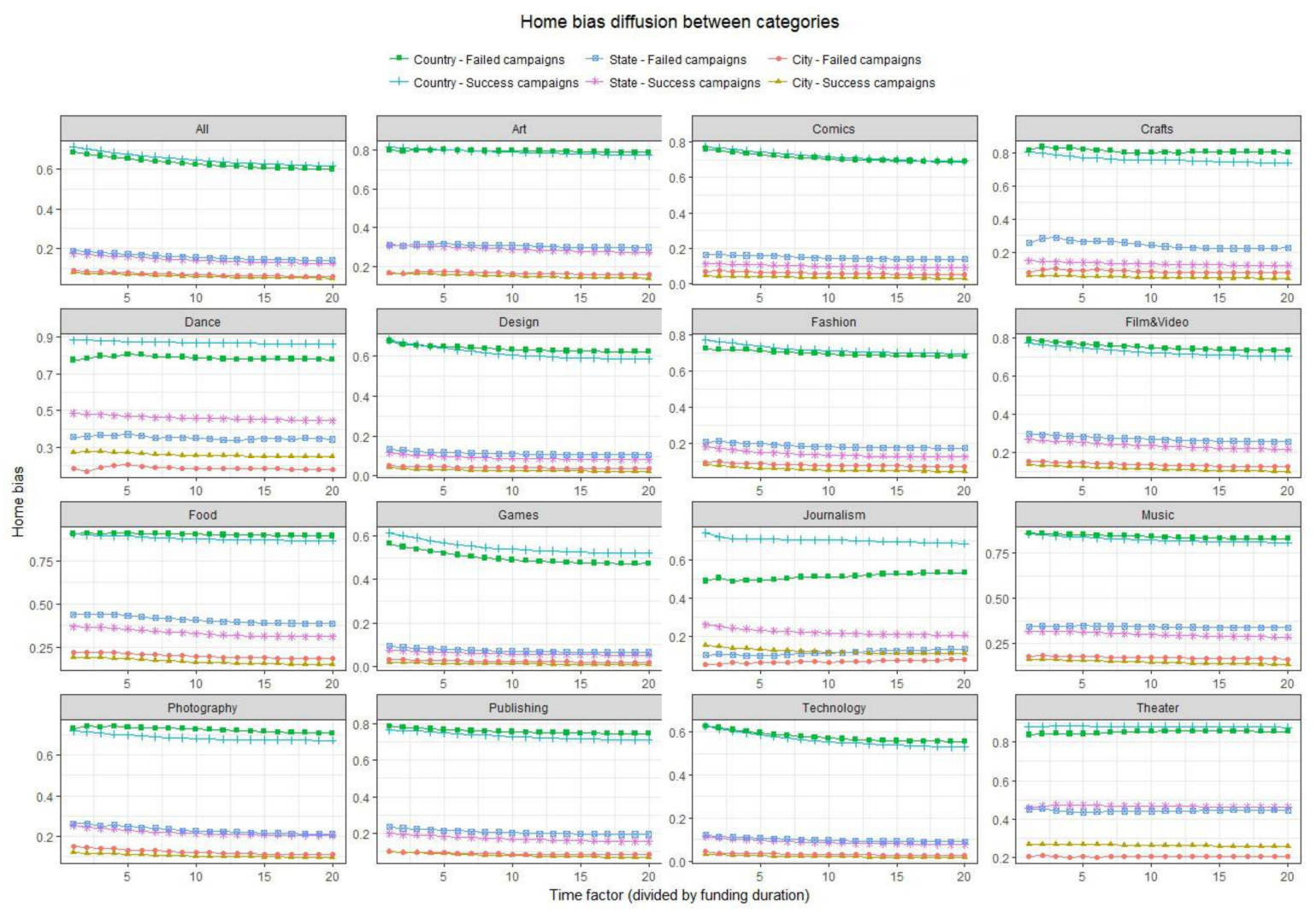

Figure 3. Home bias diffusion between categories.

Another noteworthy phenomenon is the discrimination against other countries in the food category; approximately $90 \%$ of investors only invest in campaigns from their own country. In contrast, games are the most international category, with approximately $50 \%$ of investors in game projects coming from countries different than that of the founders.

However, we must admit that the analysis at the national level is unfair because Kickstarter is a website based in the US with most of its investors and founders based in the US as well; in detail, about $87 \%$ of crowdfunding projects originate in the US, so there is an issue with imbalanced data. To overcome this bias, we remove all investors and founders outside the US from the data, leaving only investors and founders from the US for the state-level home bias analysis.

We can obtain results of state-level home bias that differ from national-level home bias: (1) Differences are shown in state-level distance-diffusion curves between successful and failed projects, with no coincidence between these curves; (2) In some categories, the state-level distance-diffusion curve of failed projects is above successful ones, such as comics, fashion, and crafts, while in other categories such as dance, publishing, and theater, the trend is the opposite. This shows the different distance diffusion patterns between categories; (3) Overall, the state-level distance-diffusion curve is flat in most categories, while in other categories such as photography, publishing, and film \& video projects, it declines very rapidly, indicating that state-level distance spreads quickly in these campaigns. 
If we subdivide and examine whether investors and founders are from the same city, city-level distance diffusion can be obtained. Overall, city-level home bias shows a declining trend and presents apparent differences between successful and failed campaigns. The distance-diffusion trend curve of failed projects is located above successful ones for art, comics, crafts, design, and fashion; that is, investors with a weaker home bias need to be involved if these project categories are to be funded successfully. In contrast, the distance-diffusion trend curve of successful projects is located above failed ones for the categories of dance, journalism, and theater, which indicates that the support of investors from far distances is a factor helps the project be successfully funded.

There are a number of categories in which the distance-diffusion curve of successful projects differs greatly from failed ones, such as dance, crafts and theater, which shows an obvious difference in the behavior patterns of backers between successful and failed campaigns. These investors are more influenced by the distance factor when they evaluate the campaigns. In contrast, in other projects, the distance-diffusion curve of successful projects is close to that of failed ones, such as games, technology and publishing, which indicates that the distance factor will have a much smaller influence on investors. Furthermore, some categories present a steep distance-diffusion curve. Examples include food and journalism; this indicates that distance is expanding faster in such projects than in any other campaigns. Other categories, such as games and theater, show relatively smooth distance-diffusion curves, which indicates that the speed of distance diffusion for such projects is slow.

The great differences between categories may be caused by the nature of the projects themselves and the preferences of the investors, among which technology projects and theater projects are two opposite examples. Transnational investment on technology projects is a common investment phenomenon, therefore the home bias for technology projects on the national level is not obvious. On the contrary, culture shows a significant impact on theater projects because investors tend to invest in the projects with similar culture [26,27]. The difference in the nature of such projects directly leads to differences in the behavioral pattern of the investors. Investors of theater projects prefer to invest in the projects in the same country as the fundraisers. This phenomenon is particularly evident in the state level and city level. That is, investors prefer theater projects from the same state or city. Another possible reason is the offline market's impact on online finance. In general, campaigns such as food and theater rely strongly on geographical position. Investors prefer projects with the similar culture and habits as themselves, therefore the offline preference affects the behavior patterns of online investment of the crowdfunding pitch.

However, we have to pay attention that in some categories, home bias does not seem to be evident, such as technology, design, and comics projects. Such projects have generally objective evaluation criteria which do not change with differences in the culture, education, social status, and geographical location of the investors. Therefore, for such campaigns, investors inspected the campaigns from the perspective of project quality rather than the geographical factors. Thus, social relationship factors have a much smaller impact on the project investment. This has important implications for the fundraiser of the crowdfunding campaigns, because the extant research and application almost do not discriminate between the differences in the categories. Most of the extant research conclusions are made from the pool data of all campaigns without attempting to distinguish between categories.

Taking the game campaign as an example, the evaluation standards of investors for these projects are more focused on quality than the geographical location of the founders. In the game category, only $0.91 \%$ of the investors came from the same city as the fundraisers in the anaphase of the funding duration (last 1/3). That is, in the investment of game projects, investors will not support the crowdfunding projects because of the geographical position of the founders. On the contrary, since investors are distributed in a wide area, these investors care more about the quality of the project itself rather than the location which determines whether the project is worth investing. Founders of such projects should improve the quality of the project in order to attract investors. At the same time, there should be a larger scope for the promotion of the project, and a wide range of promotion is 
more effective than small-scale promotion. The opposite example includes the food category where fundraisers should pay close attention to the investors who are geographically close.

The study provides a preliminary analysis to compare the difference between categories in fine-grained home bias in a dynamic way.

\subsection{Financial Impact of Distance Diffusion of Home Bias}

Table 2 shows the financial impact of home bias for projects with over 200 investors through a logit model. It shows that the impact at the national, state, and city levels on pledge results increases in turn with $2.031^{* * *}, 3.715^{* * *}$, and $5.016^{* * *}$, respectively. In other words, the project will more likely be funded successfully if it attracts more investments from local investors.

Table 2. Financial impact of home bias for projects with over 200 investors (logit).

\begin{tabular}{|c|c|c|c|c|}
\hline Variable & National Level & State Level & City Level & Distance \\
\hline $\operatorname{logNumUpdates}$ & $\begin{array}{l}1.359^{* * *} \\
(0.0702)\end{array}$ & $\begin{array}{l}1.342 * * * \\
(0.0703)\end{array}$ & $\begin{array}{l}1.335^{* * *} \\
(0.0696)\end{array}$ & $\begin{array}{l}1.353^{* * *} \\
(0.0705)\end{array}$ \\
\hline $\log$ Num Comment & $\begin{array}{c}0.1743^{* * *} \\
(0.0383)\end{array}$ & $\begin{array}{l}0.252 * * * \\
(0.0394)\end{array}$ & $\begin{array}{c}0.2054^{* * *} \\
(0.0391)\end{array}$ & $\begin{array}{l}0.243^{* * *} \\
(0.0401)\end{array}$ \\
\hline $\log$ Goal & $\begin{array}{c}-2.696^{* * *} \\
(0.081)\end{array}$ & $\begin{array}{c}-2.786^{* * *} \\
(0.0831)\end{array}$ & $\begin{array}{c}-2.749 * * * \\
(0.082)\end{array}$ & $\begin{array}{c}-2.693 * * * \\
(0.0813)\end{array}$ \\
\hline logLastdays & $\begin{array}{l}-0.1479 \\
(0.1781)\end{array}$ & $\begin{array}{l}-0.1209 \\
(0.1826)\end{array}$ & $\begin{array}{l}-0.1043 \\
(0.1794)\end{array}$ & $\begin{array}{c}-0.1448 \\
(0.181)\end{array}$ \\
\hline logNumPledgeLevel & $\begin{array}{c}-0.3241^{* * *} \\
(0.1046)\end{array}$ & $\begin{array}{c}-0.2952^{* * *} \\
(0.105)\end{array}$ & $\begin{array}{c}-0.2761^{* * *} \\
(0.1042)\end{array}$ & $\begin{array}{c}-0.3711^{* * *} \\
(0.1054)\end{array}$ \\
\hline Video & $\begin{array}{c}0.8863 * * * \\
(0.2143)\end{array}$ & $\begin{array}{c}0.8219 * * * \\
(0.2134)\end{array}$ & $\begin{array}{c}0.7855 * * * \\
(0.2107)\end{array}$ & $\begin{array}{c}0.8555^{* * *} \\
(0.2148)\end{array}$ \\
\hline $\log$ NumPreceding & $\begin{array}{c}-0.1901^{* * *} \\
(0.0426)\end{array}$ & $\begin{array}{c}-0.1565^{* * *} \\
(0.0424)\end{array}$ & $\begin{array}{c}-0.1626^{* * *} \\
(0.0421)\end{array}$ & $\begin{array}{c}-0.1379 * * * \\
(0.0425)\end{array}$ \\
\hline $\log$ NumFollowers & $\begin{array}{c}0.0221 \\
(0.0143) \\
\end{array}$ & $\begin{array}{c}0.0208 \\
(0.0144) \\
\end{array}$ & $\begin{array}{c}0.0231 \\
(0.0143) \\
\end{array}$ & $\begin{array}{c}0.023 \\
(0.0143) \\
\end{array}$ \\
\hline logMaxPledge & $\begin{array}{c}0.1155^{* * *} \\
(0.0313)\end{array}$ & $\begin{array}{c}0.1244^{* * *} \\
(0.0316)\end{array}$ & $\begin{array}{c}0.1242^{* * *} \\
(0.0314)\end{array}$ & $\begin{array}{c}0.1085^{* * *} \\
(0.0314)\end{array}$ \\
\hline logMinPledge & $\begin{array}{l}0.068^{* * *} \\
(0.0252)\end{array}$ & $\begin{array}{l}0.064^{* *} \\
(0.0252)\end{array}$ & $\begin{array}{c}0.0673 * * * \\
(0.0251)\end{array}$ & $\begin{array}{l}0.063 * * \\
(0.0251)\end{array}$ \\
\hline $\log$ AvgPledge & $\begin{array}{c}0.876^{* * *} \\
(0.0577)\end{array}$ & $\begin{array}{c}0.8378 * * * \\
(0.0578)\end{array}$ & $\begin{array}{l}0.85^{* * *} \\
(0.0575)\end{array}$ & $\begin{array}{c}0.8709 * * * \\
(0.0576)\end{array}$ \\
\hline logPopulationDensity & $\begin{array}{c}-0.0263 \\
(0.0575)\end{array}$ & $\begin{array}{l}-0.092 \\
(0.057)\end{array}$ & $\begin{array}{c}-0.1518^{* * *} \\
(0.0582)\end{array}$ & $\begin{array}{l}-0.0565 \\
(0.0609)\end{array}$ \\
\hline CountryBias & $\begin{array}{c}2.031 * * * \\
(0.1806)\end{array}$ & & & \\
\hline StateBias & & $\begin{array}{c}3.715^{* * *} \\
(0.303)\end{array}$ & & \\
\hline CityBias & & & $\begin{array}{l}5.016^{* * *} \\
(0.5215)\end{array}$ & \\
\hline logDistance & & & & $\begin{array}{c}-1.004^{* * *} \\
(0.0878)\end{array}$ \\
\hline constant & $\begin{array}{l}19.39^{* * *} \\
(0.9417)\end{array}$ & $\begin{array}{l}21.12 * * * \\
(0.9403)\end{array}$ & $\begin{array}{l}21.24^{* * *} \\
(0.9309)\end{array}$ & $\begin{array}{c}28.77^{* * *} \\
(1.158)\end{array}$ \\
\hline Pseudo R2 & 0.5045 & 0.5136 & 0.5048 & 0.5083 \\
\hline Observations & 10,160 & 10,160 & 10,160 & 10,159 \\
\hline
\end{tabular}


For the distance between investors and founders, the closer the two sides are, the more likely it will be that the project is successful; the coefficient is $-1.004^{* * *}$. The negative coefficient means that the farther the distance is, the less likely it is to be successful in funding. This is consistent with the financial impact of home bias at the national, state, and city levels.

In the model, we control the population density because we believe that both home bias and distance diffusion are affected by the population density of the project location. For example, $100 \mathrm{~km}$ in Canada is a significantly different proposition than $100 \mathrm{~km}$ in the Netherlands. In terms of the regression coefficient, although the impact is negative in other models, population density only has a significant effect at the city level. This shows that at the city level, population density will affect the financing results of the crowdfunding projects, that is, launching crowdfunding projects in densely populated cities will reduce the possibility of successful funding. However, this conclusion does not hold at the national and state levels, as well as in the distance-level model.

The marginal effect of distance is the change in the success ratio for projects based on the discrete change of the dummy variable (from 0 to 1), as shown in the Table 3; it shows that all the marginal effects are significant for national-, state-, city-, and distance-level home bias. In detail, the marginal effects are significantly positively correlated for national-, state-, and city-level home bias, with $0.0354^{* * *}, 0.061^{* * *}$, and $0.0855^{* * *}$, respectively. The city-level home bias shows the maximum energy with regards to successful campaigns, which is to say that while the other conditions are equal (proportionally equal changes from investors in the same city with respect to the same country and the same state), the pledge results are impacted most significantly. Meanwhile, the marginal effect is significantly negatively correlated with the distance level with $-0.0172 * * *$, which means that for each additional unit of distance between the investor and the founders, the project's success rate will decrease by $1.72 \%$.

Table 3. Marginal effects based on the discrete change of the dummy variable from 0 to 1 for projects with over 200 investors (logit).

\begin{tabular}{|c|c|c|c|c|}
\hline Variable & National-Level dy/dx & State-Level dy/dx & City-Level dy/dx & Distance $\mathrm{dy} / \mathrm{d} \mathrm{x}$ \\
\hline $\log N u m U p d a t e s$ & $\begin{array}{c}0.0237^{* * *} \\
(0.0019)\end{array}$ & $\begin{array}{c}0.0221 * * * \\
(0.0018)\end{array}$ & $\begin{array}{c}0.0227 * * * \\
(0.0018)\end{array}$ & $\begin{array}{c}0.0232 * * * \\
(0.0018)\end{array}$ \\
\hline $\log$ NumComment & $\begin{array}{c}0.003^{* * *} \\
\left(6.7 \times 10^{-4}\right)\end{array}$ & $\begin{array}{c}0.0041^{* * *} \\
\left(6.7 \times 10^{-4}\right)\end{array}$ & $\begin{array}{c}0.0035^{* * *} \\
\left(6.7 \times 10^{-4}\right)\end{array}$ & $\begin{array}{c}0.0042^{* * *} \\
\left(7.0 \times 10^{-4}\right)\end{array}$ \\
\hline $\log$ Goal & $\begin{array}{c}-0.0469 * * * \\
(0.0029)\end{array}$ & $\begin{array}{c}-0.0458^{* * *} \\
(0.0029)\end{array}$ & $\begin{array}{c}-0.0468^{* * * *} \\
(0.003)\end{array}$ & $\begin{array}{c}-0.0462 \text { **** } \\
(0.0029)\end{array}$ \\
\hline $\log$ Lastdays & $\begin{array}{l}-0.0026 \\
(0.0031)\end{array}$ & $\begin{array}{l}-0.002 \\
(0.003)\end{array}$ & $\begin{array}{l}-0.0018 \\
(0.0031)\end{array}$ & $\begin{array}{l}-0.0025 \\
(0.0031)\end{array}$ \\
\hline logNumPledgeLevel & $\begin{array}{c}-0.0056^{* * *} \\
(0.0018)\end{array}$ & $\begin{array}{c}-0.0049^{* * *} \\
(0.0017)\end{array}$ & $\begin{array}{c}-0.0047^{* * * *} \\
(0.0018)\end{array}$ & $\begin{array}{c}-0.0064^{* * * *} \\
(0.0018)\end{array}$ \\
\hline Video & $\begin{array}{c}0.0232 * * * \\
(0.008)\end{array}$ & $\begin{array}{c}0.0197 * * * \\
(0.0072)\end{array}$ & $\begin{array}{c}0.0192 * * * \\
(0.0071)\end{array}$ & $\begin{array}{c}0.0217^{* * *} \\
(0.0078)\end{array}$ \\
\hline $\log$ NumPreceding & $\begin{array}{l}-0.0033^{* * *} \\
\left(7.7 \times 10^{-4}\right)\end{array}$ & $\begin{array}{l}-0.0026^{* * *} \\
\left(7.1 \times 10^{-4}\right)\end{array}$ & $\begin{array}{l}-0.0028^{* * *} \\
\left(7.4 \times 10^{-4}\right)\end{array}$ & $\begin{array}{l}-0.0024^{* * *} \\
\left(7.4 \times 10^{-4}\right)\end{array}$ \\
\hline $\log$ NumFollowers & $\begin{array}{c}3.9 \times 10^{-4} \\
\left(2.5 \times 10^{-4}\right)\end{array}$ & $\begin{array}{c}3.4 \times 10^{-4} \\
\left(2.4 \times 10^{-4}\right) \\
\end{array}$ & $\begin{array}{c}3.9 \times 10^{-4} \\
\left(2.5 \times 10^{-4}\right) \\
\end{array}$ & $\begin{array}{c}3.9 \times 10^{-4} \\
\left(2.5 \times 10^{-4}\right) \\
\end{array}$ \\
\hline logMaxPledge & $\begin{array}{c}0.002 * * * \\
\left(5.6 \times 10^{-4}\right)\end{array}$ & $\begin{array}{c}0.002^{* * *} \\
\left(5.3 \times 10^{-4}\right)\end{array}$ & $\begin{array}{c}0.0021^{* * *} \\
\left(5.5 \times 10^{-4}\right)\end{array}$ & $\begin{array}{c}0.0019^{* * *} \\
\left(5.5 \times 10^{-4}\right)\end{array}$ \\
\hline logMinPledge & $\begin{array}{c}0.0012^{* * *} \\
\left(4.4 \times 10^{-4}\right)\end{array}$ & $\begin{array}{c}0.0011^{* *} \\
\left(4.2 \times 10^{-4}\right)\end{array}$ & $\begin{array}{c}0.0011^{* * *} \\
\left(4.3 \times 10^{-4}\right)\end{array}$ & $\begin{array}{c}0.0011^{* *} \\
\left(4.4 \times 10^{-4}\right)\end{array}$ \\
\hline logAvgPledge & $\begin{array}{c}0.0153^{* * *} \\
(0.0013)\end{array}$ & $\begin{array}{c}0.0138^{* * *} \\
(0.0012)\end{array}$ & $\begin{array}{c}0.0145^{* * *} \\
(0.0013)\end{array}$ & $\begin{array}{c}0.0149^{* * *} \\
(0.0013)\end{array}$ \\
\hline
\end{tabular}


Table 3. Cont.

\begin{tabular}{|c|c|c|c|c|}
\hline Variable & National-Level dy/dx & State-Level dy/dx & City-Level dy/dx & Distance $\mathrm{dy} / \mathrm{d} \mathrm{x}$ \\
\hline logPopulationDensity & $\begin{array}{c}-4.6 \times 10^{-4} \\
(0.001)\end{array}$ & $\begin{array}{c}-0.0015 \\
\left(9.4 \times 10^{-4}\right)\end{array}$ & $\begin{array}{c}-0.0026^{* * *} \\
(0.001)\end{array}$ & $\begin{array}{c}-9.7 \times 10^{-4} \\
(0.001)\end{array}$ \\
\hline CountryBias & $\begin{array}{c}0.0354 * * * \\
(0.0038)\end{array}$ & & & \\
\hline StateBias & & $\begin{array}{l}0.061^{* * *} \\
(0.0061)\end{array}$ & & \\
\hline CityBias & & & $\begin{array}{c}0.0855^{* * *} \\
(0.01)\end{array}$ & \\
\hline $\log$ Distance & & & & $\begin{array}{c}-0.0172 \text { *** } \\
(0.0018)\end{array}$ \\
\hline Observations & 10,160 & 10,160 & 10,160 & 10,160 \\
\hline
\end{tabular}

\subsection{Distance Versus Social Relationships}

Although we have demonstrated the diffusion trends of investors' distance, we do not discuss the impact of home bias and social relationships on the funding results. Some extant studies show that home bias and social relationships are significantly correlated [16], thus distance effects may be a likely proxy of social relationships.

As it is difficult to exclude founders' social relationships from the analysis, it is impossible to identify whether the backers truly were strangers or simply friends living in another city or state. This could potentially be done by using the founders' social networks as a proxy, because the more extensive the social network is, the more friends there are in the corresponding node. It is also likely that these friends already have built social relationships offline [41]. The Pearson correlation coefficient between the number of backers and distance is $0.493^{* * *}(p<0.001)$, that is, the closer the investor and financier, the more backers of the campaigns are. This indicates, from the geographical distance, that a part of social friends should be closer to the investor. Therefore, nodes with extensive social relationships may be more affected by distance.

In order to analyze distance versus social relationships for funding results, we attempted to examine the moderated effect of distance and social relationships, as shown in Table 4, where $\log$ NumFollowers indicates the number followers on online social platforms (including facebook.com, twitter.com, flickr.com, etc.).

The results of distance versus social relationships show that the social relationships weaken the effect of distance on the funding results (0.0031); meanwhile, the distance weakens the impact of social relationships on the funding results $\left(-0.4023^{* * *}\right)$. The moderate effect of social relationships on funding results is negatively impacted by the distance, that is, the distance between founders and backers weakens the impact of social relationships. The results indicate that some investors are acquaintances of the founders. Therefore, home bias, to some extent, is influenced by the social relationships of founders.

At the same time, the moderate effect of distance on funding results is negatively impacted by social relationships $\left(-0.3036^{* * *}\right)$. In other words, the distance factor and social relationships show certain substitution effects, which is to say that some investors are friends or family members of founders, which leads to the negative influence. 
Table 4. Results of distance versus social relationships.

\begin{tabular}{|c|c|c|c|c|c|c|}
\hline \multirow{2}{*}{ Variable } & \multicolumn{6}{|c|}{ Model } \\
\hline & (1) & (2) & (3) & (4) & (5) & (6) \\
\hline $\log N u m U p d a t e s$ & $\begin{array}{c}1.363^{* * *} \\
(0.069)\end{array}$ & $\begin{array}{l}1.357^{* * *} \\
(0.0704)\end{array}$ & $\begin{array}{l}1.353^{* * *} \\
(0.0705)\end{array}$ & $\begin{array}{l}1.355^{* * *} \\
(0.0705)\end{array}$ & $\begin{array}{l}1.417^{* * *} \\
(0.0707)\end{array}$ & $\begin{array}{l}1.396^{* * *} \\
(0.0717)\end{array}$ \\
\hline $\log \mathrm{NumComment}$ & $\begin{array}{c}0.0467 \\
(0.0362)\end{array}$ & $\begin{array}{c}0.2357^{* * *} \\
(0.0399)\end{array}$ & $\begin{array}{l}0.243^{* * *} \\
(0.0401)\end{array}$ & $\begin{array}{l}0.2376^{* * *} \\
(0.0401)\end{array}$ & $\begin{array}{l}0.1245^{* * *} \\
(0.0375)\end{array}$ & $\begin{array}{l}0.2663^{* * *} \\
(0.0406)\end{array}$ \\
\hline $\log$ Goal & $\begin{array}{c}-2.716^{* * *} \\
(0.0799)\end{array}$ & $\begin{array}{c}-2.698^{* * *} \\
(0.0813)\end{array}$ & $\begin{array}{c}-2.693 * * * \\
(0.0813)\end{array}$ & $\begin{array}{c}-2.696^{* * *} \\
(0.0814)\end{array}$ & $\begin{array}{c}-2.716^{* * *} \\
(0.0809)\end{array}$ & $\begin{array}{c}-2.695^{* * *} \\
(0.0818)\end{array}$ \\
\hline $\log$ Lastdays & $\begin{array}{l}-0.1745 \\
(0.1733)\end{array}$ & $\begin{array}{l}-0.1482 \\
(0.1811)\end{array}$ & $\begin{array}{c}-0.1448 \\
(0.181)\end{array}$ & $\begin{array}{l}-0.1471 \\
(0.1811)\end{array}$ & $\begin{array}{l}-0.1772 \\
(0.1763)\end{array}$ & $\begin{array}{l}-0.1577 \\
(0.1821)\end{array}$ \\
\hline logNumPledgeLevel & $\begin{array}{l}-0.2142^{* *} \\
(0.1016)\end{array}$ & $\begin{array}{l}-0.3638^{* * *} \\
(0.1053)\end{array}$ & $\begin{array}{c}-0.3711^{* * *} \\
(0.1054)\end{array}$ & $\begin{array}{l}-0.3654^{* * *} \\
(0.1053)\end{array}$ & $\begin{array}{l}-0.3223^{* * *} \\
(0.1043)\end{array}$ & $\begin{array}{c}-0.4267^{* * *} \\
(0.1068)\end{array}$ \\
\hline Video & $\begin{array}{c}0.8167^{* * *} \\
(0.2091)\end{array}$ & $\begin{array}{l}0.869^{* * * *} \\
(0.2142)\end{array}$ & $\begin{array}{c}0.8555^{* * *} \\
(0.2148)\end{array}$ & $\begin{array}{l}0.865^{* * *} \\
(0.2144)\end{array}$ & $\begin{array}{l}0.8545^{* * *} \\
(0.212)\end{array}$ & $\begin{array}{c}0.8623^{* * *} \\
(0.2164)\end{array}$ \\
\hline logNumPreceding & $\begin{array}{l}-0.1524^{* * *} \\
(0.0416)\end{array}$ & $\begin{array}{l}-0.1224^{* * *} \\
(0.0414)\end{array}$ & $\begin{array}{c}-0.1379^{* * *} \\
(0.0425)\end{array}$ & $\begin{array}{c}-0.1268^{* * *} \\
(0.0424)\end{array}$ & $\begin{array}{l}-0.1626^{* * *} \\
(0.0426)\end{array}$ & $\begin{array}{c}-0.1476^{* * *} \\
(0.0431)\end{array}$ \\
\hline logMaxPledge & $\begin{array}{c}0.1306^{* * *} \\
(0.0308)\end{array}$ & $\begin{array}{c}0.1097 * * * \\
(0.0314)\end{array}$ & $\begin{array}{c}0.1085^{* * *} \\
(0.0314)\end{array}$ & $\begin{array}{l}0.1094^{* * *} \\
(0.0314)\end{array}$ & $\begin{array}{l}0.1205^{* * *} \\
(0.0312)\end{array}$ & $\begin{array}{l}0.1042 * * * \\
(0.0317)\end{array}$ \\
\hline logMinPledge & $\begin{array}{c}0.0641^{* * *} \\
(0.0249)\end{array}$ & $\begin{array}{l}0.0624^{* *} \\
(0.0251)\end{array}$ & $\begin{array}{l}0.063 * * \\
(0.0251)\end{array}$ & $\begin{array}{c}0.0626^{* *} \\
(0.0251)\end{array}$ & $\begin{array}{c}0.0626^{* *} \\
(0.0252)\end{array}$ & $\begin{array}{c}0.0627^{* *} \\
(0.0253)\end{array}$ \\
\hline logAvgPledge & $\begin{array}{l}0.8777^{* * *} \\
(0.0566)\end{array}$ & $\begin{array}{l}0.8732^{* * *} \\
(0.0576)\end{array}$ & $\begin{array}{l}0.8709^{* * *} \\
(0.0576)\end{array}$ & $\begin{array}{l}0.8728^{* * *} \\
(0.0576)\end{array}$ & $\begin{array}{l}0.8487^{* * *} \\
(0.0572)\end{array}$ & $\begin{array}{l}0.8487^{* * *} \\
(0.0579)\end{array}$ \\
\hline logPopulationDensity & $\begin{array}{l}-0.2171^{* * *} \\
(0.0602)\end{array}$ & $\begin{array}{c}-0.0562 \\
(0.061)\end{array}$ & $\begin{array}{l}-0.0565 \\
(0.0609)\end{array}$ & $\begin{array}{c}-0.0564 \\
(0.061)\end{array}$ & $\begin{array}{l}-0.1666^{* * *} \\
(0.0606)\end{array}$ & $\begin{array}{l}-0.0461 \\
(0.0612)\end{array}$ \\
\hline logNumFollowers & $\begin{array}{l}0.0286^{* *} \\
(0.014)\end{array}$ & & $\begin{array}{c}0.023 \\
(0.0143)\end{array}$ & & $\begin{array}{l}0.9018^{* * *} \\
(0.0864)\end{array}$ & $\begin{array}{c}0.6871^{* * *} \\
(0.0922)\end{array}$ \\
\hline $\log$ Distance & & $\begin{array}{l}-1.009 * * * \\
(0.0878)\end{array}$ & $\begin{array}{l}-1.004^{* * * *} \\
(0.0878)\end{array}$ & $\begin{array}{l}-1.009 \text { **** } \\
(0.0878)\end{array}$ & & $\begin{array}{l}-.8342 * * * \\
(0.0904)\end{array}$ \\
\hline $\begin{array}{c}\operatorname{logNumFollowers} * \\
\text { logDistance }\end{array}$ & & & & $\begin{array}{c}0.0031 \\
(0.0065)\end{array}$ & $\begin{array}{c}-0.4023 * * * \\
(0.0389)\end{array}$ & $\begin{array}{c}-0.3036^{* * *} \\
(0.0414)\end{array}$ \\
\hline constant & $\begin{array}{l}21.8^{* * *} \\
(0.917)\end{array}$ & $\begin{array}{c}28.89 * * * \\
(1.156)\end{array}$ & $\begin{array}{c}28.77^{* * * *} \\
(1.158)\end{array}$ & $\begin{array}{c}28.87^{* * * *} \\
(1.157)\end{array}$ & $\begin{array}{l}21.85 \text { *** } \\
(0.9316)\end{array}$ & $\begin{array}{c}27.64^{* * *} \\
(1.169)\end{array}$ \\
\hline Pseudo R2 & 0.4872 & 0.5080 & 0.5083 & 0.5080 & 0.5026 & 0.5159 \\
\hline Observations & 10,160 & 10,159 & 10,159 & 10,159 & 10,159 & 10,159 \\
\hline
\end{tabular}

\section{Discussion and Conclusions}

This study investigates the dynamics of home bias in crowdfunding investment and the distance diffusion of home bias in the crowdfunding market, as well as the financial impact of the distance diffusion of home bias on pledge results. Through data mining and econometric models, we validate the existence of distance diffusion of home bias in crowdfunding and find that the investor's behavior pattern regarding dynamic home bias affects the success rate of campaigns in the crowdfunding pitch. In particular, we try to answer two key questions in this study: (1) How is distance spread out in crowdfunding investment, and are there any differences between categories? (2) What is the economic value of home bias and distance diffusion? Additionally, how do distance diffusion and home bias affect the financial performance of the projects?

In the extant literature, there is little research on home bias under reward-based crowdfunding, but there are some studies on other crowdfunding modes, such as P2P lending [1] and equity crowdfunding [42]. The P2P lending study uncovers home bias and validates the influence of home bias on online investments [1], while in the equity study the relationship between equity 
home bias and financial integration is found to be U-shaped [42]. Another equity crowdfunding platform, ASSOB, presents evidence of the influence of geographic distance among retail, accredited, and overseas investors and venture locations in an equity crowdfunding context. Geographic distance is negatively correlated with investment probability for home country investors; however, investment decisions differ by investor type [43]. However, in the reward-based crowdfunding mode, few relevant theoretical explorations and practical implications exist.

In the few studies we can find, there is little research on home bias, especially for the research on Internet finance. In the most relevant study, P2P lending is adopted as the research object. There, the authors mainly discussed two questions: (1) Is there home bias in online debt-based crowdfunding market? (2) If so, what is the mechanism that drives home bias in this market? Results from a series of tests consistently refuted a purely economic explanation of home bias—including variance-based statistical discrimination — and supported the argument that behavioral factors at least partially drive home bias behaviors. The paper documents empirical evidence of home bias in online crowdfunding and tries to tease out the mechanism behind it [20]. In this paper, we employ the reward-based crowdfunding as the study object which compensates for the lack of existing research on reward-based model. Further, we provide solid evidence for the existence of home bias in the reward-based crowdfunding. The conclusion of this study also provides improvement for the extant works and provides creative solutions for practice.

Many extant studies explains the home bias according to the influence of offline social relationships on online behavior. They often conclude that the influence of offline social networks extends to online business. Therefore, investors from closer distances have significant home bias trends. However, in this paper, we have shown that in addition to the influence of social network, home bias does exist and works in the reward-based crowdfunding pitch.

Many studies consider the home bias as a static variable, in which user behavior tends to occur in a certain area, rather than breaking the regional restrictions. For example, transactions within a province are always more than that of between provinces. Researchers generally believe that this is due to transaction costs and cultural dependence. However, the extant studies almost does not consider the changes in home bias of the investors in the funding time window. Since crowd-funding investment behavior is completed within a certain time window, investors can continue to invest within this time window. Therefore, investors' home bias can be expressed as a dynamic behavior, that is, the investors' preference can be split into early stage, middle stage, and late stage. The study shows that in the early stage of financing, investors from relatively close distances occupy a large proportion, and as financing proceeds, many remote financers gradually participate in investment, and therefore, it shows a typical distance diffusion of home bias. This phenomenon has not been studied in extant studies and practice.

Extant studies mainly discuss the source of crowdfunding investors from the perspective of social relationships. Due to the social relationships of the fundraisers, the crowdfunding campaigns often attract seminal investors in the early stage of funding, among which, most of the backers in the early stage are the friends or family members of the founders. Therefore, in the early stage of financing, the distance between investors and backers is close. However, these studies ignore the economic value of home bias. That is, when backers from closer distances participate in investment, are crowdfunding projects more likely to succeed or fail? This study shows that the farther the distance between investors and financiers is, the less likely it is for the project to succeed. In other words, a near-distance investment is conducive to the successful financing of the projects. It is similar to the influence of offline financing. In offline investments, a closer distance means that investors have a better understanding of the capabilities and credits of the founders.

Our study adds new insights to the literature by theorizing and empirically testing the effects of distance diffusion of home bias on performance predictors such as the pledge results of crowdfunding campaigns [1] and the moderated effect of distance and social relationships [16]. Insights from this study yield both theoretical and practical implications. 


\subsection{Contribution to Theory}

As a common behavioral pattern, home bias is heavily discussed in offline markets, as the offline market is often impacted by factors related to geographical location (communication cost, contract cost, supervision cost, etc.). Many studies have therefore proven the existence of home bias in offline transactions and presented various theories to explain home bias in offline markets [44]. However, there is much less research on online markets. As an emerging Internet financial model, crowdfunding is the subject of only very few systemic studies, especially with regards to the distance diffusion of home bias. Relevant research results are rare, as can be seen in the reward-based crowdfunding mode.

Although social relationships play an important role in the financing of crowdfunding, they cannot fully explain the influence of home bias in reward-based crowdfunding. After controlling social factors, investors' home bias still significantly affects the success rate of crowdfunding campaigns. In previous studies, it was widely believed that early investors were friends or family members of financiers; therefore, the geographic distance between investors and financiers is smaller. But in theory, the explanation has two shortcomings: (1) the explanation considers home bias and its impacts from a static perspective, without a dynamic perspective to examine the relationship between investors and financiers; and (2) in the early stage of financing, due to the existence of social relationships, it is easy to attract friends of the financier to participate in the investment. However, this explanation almost ignores the influence of nonsocial relationships on investment. In fact, in addition to financiers' friends and family members, there must be a large number of strangers involved in the investment. This group of investors has affected the pledge results of campaigns and cannot be confused with social relationships. The paper's theoretical contribution is based on answers to these two questions.

Through empirical studies on 136,234 crowdfunding projects from Kickstarter, the study confirms the existence of distance diffusion in crowdfunding investment. However, distance diffusion is complicated and extremely uneven across categories. For instance, for food campaigns, significant discriminations exist in other countries; investors are more willing to invest in food projects from their own regions or from the same location [45]. In contrast, home bias shows less impact on technology projects, i.e., investors in technology projects will rapidly spread to a broad area. The differences in distance diffusion between categories reflect the inconsistency in investors' evaluation criteria. Previous studies have shown that the specialization of food crowdfunding projects, such as environment and food security [46], along with the description relating to environmental protection and food safety, are very useful in pinpointing fund raising success [47]. However, previous studies did not pay attention to the differences among the sources of investors. Investors in food crowdfunding projects demonstrate strong home bias. Investors prefer to invest in projects that are geographically closer to financiers, which may be due to the convergence of culture and eating habits. Geographic proximity often means a similarity in living habits. In terms of dynamic investment behavior, it is not easy for investors in food crowdfunding to spread farther, which was not noted in previous studies. For technology projects, the impact of geographical location is much smaller than it is for food. In other words, backers can spread quickly across a wide geographical range as long as the project is of high quality; similar examples include games. In reality, because of the quality rather than the location of the projects, many games or technology projects can quickly gain support from the global market once they are listed. Thus, investors' evaluation standards for such projects are not related to their geographic location. Instead of the office location, the founders of such projects therefore need to focus on project ideas and improve project quality.

In terms of the speed of distance spread, the distance-diffusion curves are steeper for some categories, such as game and theater, which shows that the distance between investors and founders in these campaigns can spread rapidly and expand to long-distance investors quickly, thus generating considerable long-distance investment. In contrast, in other categories, such as food and journalism, the distance-diffusion curve is relatively flat, which indicates that the distance between investors and founders of such projects spreads slowly. However, this does not mean that long-distance investors are reluctant to participate in the investment. Instead, it is likely that the number of long-distance investors 
backing the campaigns is lower than the number of local-distance investors, especially during the first phase of financing. The opposite example includes games, where long-distance investors are dominant from the first phase to the last phase.

In terms of the difference between successful and failed projects, the distance-diffusion trend curve of successful projects differs greatly from that of failed ones for dance, crafts, and theater. This indicates that there is a huge difference in behavioral patterns for investors of successful and of failed campaigns. These investors are more concerned about the distance factor when investing, and therefore home bias shows a greater impact. In contrast, the distance-diffusion trend curve of successful projects is close to that of failed ones in other projects, such as games, technology, and publishing, which indicates that the influence of the distance factor will be much smaller. In the economic sense, the difference reflects the economic value of home bias.

Existing studies on the economic value of home bias are almost all from the financial field rather than the crowdfunding pitch. A typical study is the influence of home bias on portfolio holdings, not only for equity, but also for bonds [48]. However, this type of studies lacks an examination of home bias behavior from the perspective of investor behavior. In fact, due to the particularity of the reward-based crowdfunding model, some crowdfunding projects promise to give investors a return in kind of the product. For example, the reward of a food campaign is likely to be food. Under these circumstances, it is impossible to explain the investment intention through a return on investment, such as a capital assets pricing model (CAPM), which is widely adopted in the financial field.

The study shows that the distance between investors and founders gradually increases over time, and there is very little systematic research on the distance diffusion of investment behavior. In the case of dividing the funding duration into three phases, the average distance between investors and founders in the prophase is $3605 \mathrm{~km}$, the average distance in the metaphase is $4154 \mathrm{~km}$, and the average distance in the anaphase is $4299 \mathrm{~km}$. Using another measurement, the average distance between investors and founders in the first phase is $3329 \mathrm{~km}$, while that during the last phase is $4131 \mathrm{~km}$ when the investment duration is divided evenly into 20 phases, which shows a significant distance-diffusion trend. The econometric model still shows the significant impact of distance factors on pledge results, even when the population density and social relationships are controlled. Discovering and proving the existence of distance diffusion of home bias for crowdfunding investment constitutes another theoretical contribution of this study.

At the same time, distance diffusion of home bias affects the pledge results of the projects. Viewed as collective behavior [49], whether a crowdfunding campaign will succeed or not is affected by various factors; home bias is one of these factors, but there are few systematic discussions that focus on it. Taking national-level home bias as an example, the overall investment on Kickstarter shows significant home bias at the national level, and the difference between successful projects and failed campaigns exhibits significant differences between categories. In particular, successful projects are often less affected by national-level home bias; that is, they can get more support from foreign investors.

Financial globalization that encourages optimal international portfolio investments should improve the investor protection standards (IPS) of a country, and the quality of IPS improves when the optimal international equity portfolio allocation of domestic and foreign investors is higher; in other words, biases play a role in international portfolio allocation [50]. But this does not explain the impact of home bias on pledge results in the crowdfunding pitch. That is, a successful crowdfunding project is, on the one hand, affected by the quality of the project [11], while on the other hand it is influenced by the investor's preference. However, few studies exist on the influence of investors' preferences.

Categories also show significant differences. For example, the home bias curve for technology projects is very steep, which indicates that they can gain more support from domestic investors during the early stages. With financing in place, investors gradually expanded to the global scale. In fact, the national-level home bias of technology projects is 0.54 in the 20th phase; namely, approximately $46 \%$ of investors come from different nationalities than the founders'. In contrast, theater projects do show significant differences in national-level home bias. The national-level home bias of theater 
projects is 0.84 in the 1st phase and 0.86 in the 20th phase, which demonstrates that most investors of theater projects come from the same country as the founders. In short, investors in theater projects prefer local resources. Among all campaigns, food projects exhibit the most significant discrimination in other countries; that is, approximately $90 \%$ of investors only invest in food projects from their own country. In contrast, game projects are the most international category, with approximately $50 \%$ of investors coming from different countries than the founders', which provides both theoretical and practical implications. Regarding the theoretical aspect, this is a future direction that should be deeply studied according to the category and characteristics of projects. In extant studies, the investor's behavior was rarely discussed according to the category and characteristics of the project.

\subsection{Managerial Implications}

This study provides rich implications and suggestions for founders in terms of effectively promoting the project. Most previous research did not focus on the impact of home bias on pledge results, thus many founders do not know how to promote their projects during the duration of funding, for instance, how and when to recommend their projects to potential backers. This study provides guidance that founders need in order to focus on backers in a small geographical range during the early stages of funding. To meet the requirements of investors' behavioral patterns, the recommended sequence should start in the same city, same state (province), and same country, and then expand to other areas, and this provides the basis for raising the success rate of crowdfunding campaigns.

At the same time, the proximity of geographical location often means a similarity in language and culture [51]. The study concludes that investors are more inclined to invest in projects with the same language and culture; therefore, founders should consider investors from the same language or culture [52]. However, some categories, like crafts, are not only subject to national-level home bias, but can easily obtain support from investors from different countries than the founders'. That is, for these categories, investors prefer exotic projects. Thus, founders should ignore home bias in promoting such projects and focus on a broader pool of investors during the early phase.

This paper provides evidence that home bias is one of the most important factors for investors to take part in crowdfunding campaigns. The differences in investors' evaluation standards is the main reason for the difference in the distance diffusion of home bias between categories. This difference provides a theoretical basis for founders and crowdfunding platforms on the basis of which to recommend suitable projects to investors. However, we should note that for some categories, home bias does not work, even showing a counterproductive influence.

\subsection{Limitations and Future Directions}

Although we studied the distance diffusion of home bias and its financial impact in the crowdfunding market, we admit that there exist some limitations. Directions for a future in-depth study are as follows: (1) The paper studies the distance diffusion and diffusion speed and their impacts on pledge results in reward-based crowdfunding without any in-depth analysis on other crowdfunding modes. Furthermore, as Kickstarter adopts the "All-or-Nothing" financing mode, the conclusion of this study may not be applicable to other modes, such as the "All-and-More" mode. In fact, in addition to reward-based crowdfunding, there are many other business models, such as equity-based, donation-based, and scientific crowdfunding. Thus, in future research, we plan to analyze the difference in distance diffusion of home bias under different financing modes; (2) An important theoretical basis for this study is that early investors are often the founders' friends or family members, so that the distance between the two sides is closer at an earlier stage than it is at a later point in time. However, this theory only explains the behavior of early investors but cannot explain the difference between investors' behavior patterns in the middle and late phases. The behavioral difference between the middle and late phase is significant, as shown in the results, and a theoretical improvement regarding this phenomenon is therefore a direction for future research; (3) The econometric model ignores the possible endogenous problem. This study adopts the explanation that home bias in investments leads 
to pledge results; however, another possible explanation is that investments impact home bias and then determine pledge results. Thus, we plan to employ "difference in difference" in order to solve the problem in the future; (4) The data we adopted is biased itself. As Kickstarter is a US-based website, and accordingly, the vast majority of founders and investors are from the United States. Therefore, to a certain extent, we just analyzed the home bias of American investors earlier but lacked the analysis of other countries. In the future, we plan to analyze the data from other countries, especially from different cultures and regions, and try to distinguish the differences of home bias between cultures.

Acknowledgments: This work is partially supported by the NSFC Grant (71601082, 71771177), Natural Science Foundation of Fujian Province (2017J01132), Social Science Planning Project of Fujian Province (FJ2016B075), Huaqiao University's High Level Talent Research Start Project Funding (16SKBS102) and Teaching development reform project for Huaqiao University teachers (17JF-JXGZ17), and by Ministry of Science of Technology, Taiwan (MOST 106-2511-S-003-029-MY3).

Author Contributions: Lihuan Guo and Wei Wang collected the data and wrote the paper; Lihuan Guo and Dongqiang Guo designed and performed the experiments; Wei Wang and Hongwei Wang analyzed the data; Yenchun Jim $\mathrm{Wu}$ contributed analysis tools and edited the paper.

Conflicts of Interest: The authors declare no conflict of interest.

\section{Appendix A}

Figure A1 shows the average distance between investors and founders in different phases of funding (200 plus investors). The distance between investors and founders is calculated in kilometers. The duration of the investment is divided evenly into 20 phases. As seen in Figure 1, the average distance between the two sides is $2877 \mathrm{~km}$ in the first phase. As funding progresses, the distance between the two sides spreads gradually and reaches $3217 \mathrm{~km}$ in the 8th phase before gradually decreasing to $2894 \mathrm{~km}$ in the last phase. The distance between investors and founders for the campaigns with 200 plus investors shows an n-shape trend.

Some crowdfunding projects attract very few investors, and these campaigns with small numbers of investors make it difficult to estimate the impact of distance diffusion. Therefore, in the financial impact of a home-bias testing model, we only employ the projects that are supported by more than 200 backers. The reasons for choosing these projects include the following: (1) these projects often maintain a stable trend and demonstrate the distance diffusion of home bias more obviously; (2) these projects reflect the patterns and trends of investments comprehensively and enduringly; and (3) these projects are able to demonstrate the diffusion process of home bias, which helps to evaluate the distance diffusion of home bias in crowdfunding markets. The appendix shows the data summary of the campaigns with 200 plus investors.

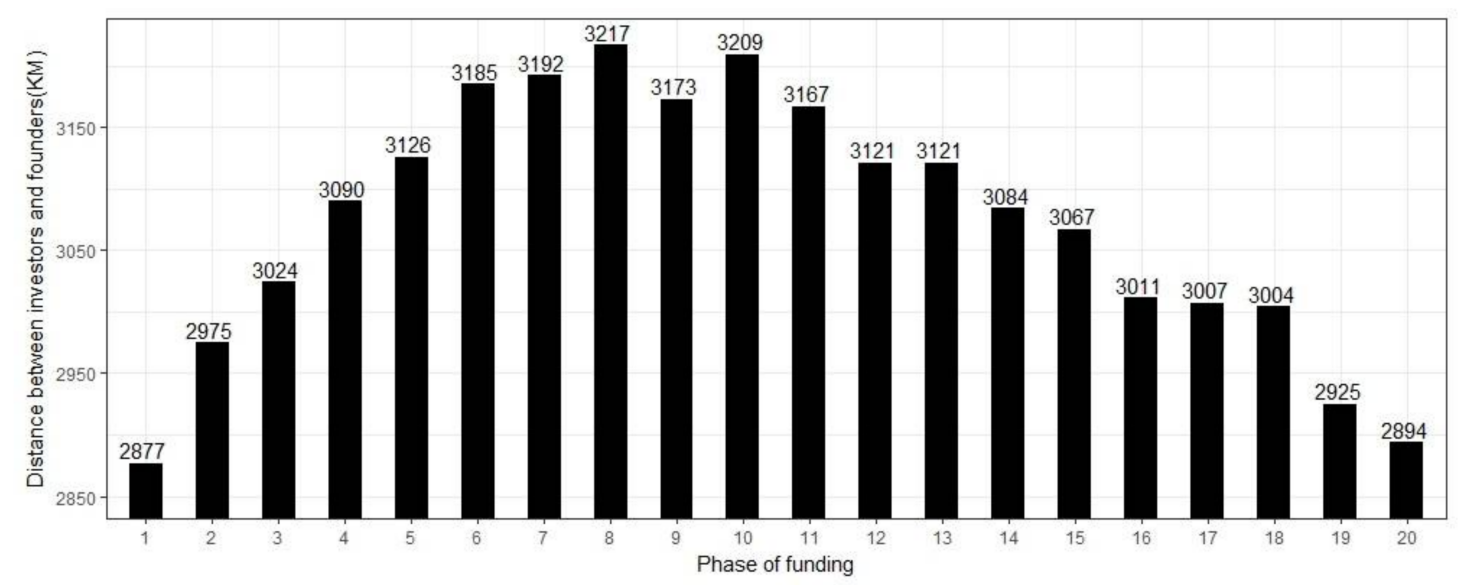

Figure A1. The average distance between investors and founders in different phases of funding (200 plus investors). 
Table A1 shows the category statistics for the sample (200 plus investors). Kickstarter's campaigns fall into 15 categories; overall, film \& video games, along with design projects, are the major parts of the sample. In terms of the success rate, the success ratio of the sub-data financing is high with average success ratio of $89.22 \%$.

Table A1. The category statistics for the sample (200 plus investors).

\begin{tabular}{ccccccccc}
\hline Category & Number & Percentage & Avg. Goal & Avg. Backer & Avg. Pledged & Progress & Success Ratio & Distance \\
\hline Art & 356 & $3.49 \%$ & $21,888.46$ & 353.50 & $23,157.73$ & $316.97 \%$ & $95.51 \%$ & 2476.36 \\
Comics & 554 & $5.43 \%$ & $11,500.02$ & 391.90 & $18,673.82$ & $255.12 \%$ & $97.65 \%$ & 3478.17 \\
Crafts & 40 & $0.39 \%$ & $12,378.88$ & 359.33 & $22,304.15$ & $802.12 \%$ & $97.50 \%$ & 3118.63 \\
Dance & 32 & $0.31 \%$ & $16,293.75$ & 271.72 & $18,968.12$ & $130.97 \%$ & $96.88 \%$ & 1650.44 \\
Design & 1396 & $13.69 \%$ & $28,682.70$ & 435.19 & $36,804.81$ & $511.05 \%$ & $83.52 \%$ & 4099.68 \\
Fashion & 346 & $3.39 \%$ & $20,163.22$ & 395.25 & $32,475.33$ & $312.30 \%$ & $94.80 \%$ & 3398.03 \\
Film \& Video & 1903 & $18.67 \%$ & $45,453.17$ & 374.66 & $35,703.44$ & $122.60 \%$ & $90.91 \%$ & 2716.93 \\
Food & 604 & $5.93 \%$ & $23,475.12$ & 338.89 & $27,262.23$ & $191.30 \%$ & $94.87 \%$ & 1529.75 \\
Games & 1848 & $18.13 \%$ & $34,320.70$ & 444.34 & $24,762.37$ & $1560.57 \%$ & $78.84 \%$ & 3962.92 \\
Journalism & 53 & $0.52 \%$ & $20,662.52$ & 381.23 & $24,620.11$ & $153.82 \%$ & $94.34 \%$ & 2909.79 \\
Music & 1179 & $11.57 \%$ & $21,497.92$ & 342.78 & $22,284.63$ & $158.88 \%$ & $97.79 \%$ & 2232.54 \\
Photography & 183 & $1.80 \%$ & $17,379.56$ & 343.53 & $24,525.91$ & $196.41 \%$ & $96.72 \%$ & 3581.74 \\
Publishing & 782 & $7.67 \%$ & $14,993.38$ & 366.41 & $20,312.96$ & $218.27 \%$ & $95.78 \%$ & 2872.05 \\
Technology & 738 & $7.24 \%$ & $61,292.66$ & 444.30 & $59,810.99$ & $304.71 \%$ & $80.22 \%$ & 4407.06 \\
Theater & 180 & $1.77 \%$ & $33,626.23$ & 350.40 & $34,574.03$ & $118.22 \%$ & $93.89 \%$ \\
\hline Sum & 10,194 & & $31,286.20$ & 393.74 & $30,526.85$ & $489.79 \%$ & $89.22 \%$ \\
\hline
\end{tabular}

For pledge goals, technology is the highest with an average of $\$ 61,292.66$, while craft is the lowest with $\$ 12,378.88$ on average. Accordingly, the highest pledged category is technology, with $\$ 59,810.99$, while the lowest is comics, with $\$ 18,673.82$. In terms of the number of backers, games attract the largest number of backers, while dance is the lowest on average. This indicates that cyber-users are more concerned with games than with dance; however, dance is much higher than games in term of the success rate $(96.88 \%$ vs. $78.84 \%)$.

\section{References}

1. Lin, M.; Viswanathan, S. Home bias in online investments: An empirical study of an online crowdfunding market. Manag. Sci. 2015, 62, 1393-1414. [CrossRef]

2. Chen, W.J.; Liaw, S.C. What is the value of eco-tourism? An evaluation of forested trails for community residents and visitors. Tour. Econ. 2012, 18, 871-885. [CrossRef]

3. Zhao, Q.; Chen, C.-D.; Wang, J.-L.; Chen, P.-C. Determinants of backers' funding intention in crowdfunding: Social exchange theory and regulatory focus. Telemat. Inform. 2017, 34, 370-384. [CrossRef]

4. Kim, T.; Por, M.H.; Yang, S.-B. Winning the crowd in online fundraising platforms: The roles of founder and project features. Electron. Commer. Res. Appl. 2017, 25, 86-94. [CrossRef]

5. Kuppuswamy, V.; Bayus, B.L. Does my contribution to your crowdfunding project matter? J. Bus. Ventur. 2017, 32, 72-89. [CrossRef]

6. Belleflamme, P.; Lambert, T.; Schwienbacher, A. Crowdfunding: Tapping the right crowd. J. Bus. Ventur. 2014, 29, 585-609. [CrossRef]

7. Gleasure, R.; Feller, J. Emerging technologies and the democratisation of financial services: A metatriangulation of crowdfunding research. Inf. Organ. 2016, 26, 101-115. [CrossRef]

8. Gerber, E.M.; Hui, J. Crowdfunding: Motivations and deterrents for participation. ACM Trans. Comput. Hum. Interact. 2013, 20, 34. [CrossRef]

9. Giudici, G.; Guerini, M.; Rossi-Lamastra, C. Reward-based crowdfunding of entrepreneurial projects: The effect of local altruism and localized social capital on proponents' success. Small Bus. Econ. 2018, 50, 307-324. [CrossRef]

10. Davis, B.C.; Hmieleski, K.M.; Webb, J.W.; Coombs, J.E. Funders' positive affective reactions to entrepreneurs' crowdfunding pitches: The influence of perceived product creativity and entrepreneurial passion. J. Bus. Ventur. 2017, 32, 90-106. [CrossRef] 
11. Xu, A.; Yang, X.; Rao, H.; Fu, W.-T.; Huang, S.-W.; Bailey, B.P. Show me the money!: An analysis of project updates during crowdfunding campaigns. In Proceedings of the 32nd Annual ACM Conference on Human Factors in Computing Systems, Toronto, ON, Canada, 26 April-1 May 2014; Association for Computing Machinery: New York, NY, USA; pp. 591-600.

12. Bi, S.; Liu, Z.; Usman, K. The influence of online information on investing decisions of reward-based crowdfunding. J. Bus. Res. 2017, 71, 10-18. [CrossRef]

13. Snyder, J.; Crooks, V.A.; Mathers, A.; Chow-White, P. Appealing to the crowd: Ethical justifications in canadian medical crowdfunding campaigns. J. Med. Ethics 2017. [CrossRef] [PubMed]

14. Cumming, D.J.; Johan, S.A. Venture Capital and Private Equity Contracting: An International Perspective; Academic Press: Cambridge, MA, USA, 2013.

15. André, K.; Bureau, S.; Gautier, A.; Rubel, O. Beyond the opposition between altruism and self-interest: Reciprocal giving in reward-based crowdfunding. J. Bus. Ethics 2017, 146, 313-332. [CrossRef]

16. Agrawal, A.; Catalini, C.; Goldfarb, A. Crowdfunding: Geography, social networks, and the timing of investment decisions. J. Econ. Manag. Strategy 2015, 24, 253-274. [CrossRef]

17. Zeng, X.; Li, Y.; Leung, S.C.; Lin, Z.; Liu, X. Investment behavior prediction in heterogeneous information network. Neurocomputing 2016, 217, 125-132. [CrossRef]

18. Mollick, E. The dynamics of crowdfunding: An exploratory study. J. Bus. Ventur. 2014, 29, 1-16. [CrossRef]

19. Zheng, H.; Xu, B.; Wang, T.; Chen, D. Project implementation success in reward-based crowdfunding: An empirical study. Int. J. Electron. Commer. 2017, 21, 424-448. [CrossRef]

20. Lin, M.; Prabhala, N.R.; Viswanathan, S. Judging borrowers by the company they keep: Friendship networks and information asymmetry in online peer-to-peer lending. Manag. Sci. 2013, 59, 17-35. [CrossRef]

21. Kgoroeadira, R.; Burke, A.; van Stel, A. Small business online loan crowdfunding: Who gets funded and what determines the rate of interest? Small Bus. Econ. 2018. [CrossRef]

22. Li, C.S.J.; Henley, J.; Ansell, J.; Dong, T.P. Location-specific factors, localisation strategy, and firm performance: A case study of taiwanese manufacturing mne subsidiaries investing in China. Tijdschr. Econ. Soc. Geogr. 2011, 102, 426-440. [CrossRef]

23. Forman, C.; Ghose, A.; Goldfarb, A. Competition between local and electronic markets: How the benefit of buying online depends on where you live. Manag. Sci. 2009, 55, 47-57. [CrossRef]

24. Graham, J.R.; Harvey, C.R.; Huang, H. Investor competence, trading frequency, and home bias. Manag. Sci. 2009, 55, 1094-1106. [CrossRef]

25. Forman, C.; Goldfarb, A.; Greenstein, S. The internet and local wages: A puzzle. Am. Econ. Rev. 2012, 102, 556-575. [CrossRef]

26. Fuchs, A.; Gehring, K. The home bias in sovereign ratings. J. Eur. Econ. Assoc. 2017, 15, 1386-1423. [CrossRef]

27. Belderbos, R.; Leten, B.; Suzuki, S. How global is R\&D? Firm-level determinants of home-country bias in R.\&D. J. Int. Bus. Stud. 2013, 44, 765-786.

28. Martínez-San Román, V.; Bengoa, M.; Sánchez-Robles, B. Foreign direct investment, trade integration and the home bias: Evidence from the european union. Empir. Econ. 2016, 50, 197-229. [CrossRef]

29. Cornand, C.; Gandré, P.; Gimet, C. Increase in home bias in the eurozone debt crisis: The role of domestic shocks. Econ. Model. 2016, 53, 445-469. [CrossRef]

30. Hnatkovska, V. Home bias and high turnover: Dynamic portfolio choice with incomplete markets. J. Int. Econ. 2010, 80, 113-128. [CrossRef]

31. Kim, H. The spatial impact of cultural distances on home bias across asian emerging markets. Atl. Econ. J. 2017, 45, 81-101. [CrossRef]

32. Hortaçsu, A.; Martínez-Jerez, F.; Douglas, J. The geography of trade in online transactions: Evidence from ebay and mercadolibre. Am. Econ. J. Microecon. 2009, 1, 53-74. [CrossRef]

33. Griffith, R.; Lee, S.; Van Reenen, J. Is distance dying at last? Falling home bias in fixed-effects models of patent citations. Quant. Econ. 2011, 2, 211-249. [CrossRef]

34. Teng, C.I.; Tseng, F.C.; Chen, Y.S.; Wu, S. Online gaming misbehaviours and their adverse impact on other gamers. Online Inf. Rev. 2012, 36, 342-358. [CrossRef]

35. Pradkhan, E. Impact of culture and patriotism on home bias in bond portfolios. Rev. Manag. Sci. 2016, 10, 265-301. [CrossRef]

36. Levy, H. What is the economic cost of the investment home bias? J. Money Credit Bank. 2017, 49, 897-929. [CrossRef] 
37. Anderson, C.W.; Fedenia, M.; Hirschey, M.; Skiba, H. Cultural influences on home bias and international diversification by institutional investors. J. Bank. Finance 2011, 35, 916-934. [CrossRef]

38. Shi, Y.; Xu, H.; Wang, M.; Conroy, P. Home bias in domestic art markets: Evidence from China. Econ. Lett. 2017, 159, 201-203. [CrossRef]

39. Mountantonakis, M.; Minadakis, N.; Marketakis, Y.; Fafalios, P.; Tzitzikas, Y. Quantifying the connectivity of a semantic warehouse and understanding its evolution over time. Int. J. Semant. Web Inf. Syst. 2016, 12, 27-78. [CrossRef]

40. Torelli, C.J.; Ahluwalia, R.; Cheng, S.Y.; Olson, N.J.; Stoner, J.L. Redefining home: How cultural distinctiveness affects the malleability of in-group boundaries and brand preferences. J. Consum. Res. 2017, 44, 44-61. [CrossRef]

41. Subrahmanyam, K.; Reich, S.M.; Waechter, N.; Espinoza, G. Online and offline social networks: Use of social networking sites by emerging adults. J. Appl. Dev. Psychol. 2008, 29, 420-433. [CrossRef]

42. Mukherjee, R.; Paul, S.; Shankar, S. Equity home bias-A global perspective from the shrunk frontier. Econ. Anal. Policy 2018, 57, 9-21. [CrossRef]

43. Günther, C.; Johan, S.; Schweizer, D. Is the crowd sensitive to distance?-How investment decisions differ by investor type. Small Bus. Econ. 2018, 50, 289-305. [CrossRef]

44. Baschieri, G.; Carosi, A.; Mengoli, S. Family firm local involvement and the local home bias phenomenon. Long Range Plan. 2017, 50, 93-107. [CrossRef]

45. Brunori, G.; Barjolle, D.; Van Broekhuizen, R.; Colombo, L.; Giampietro, M.; Kirwan, J.; Lang, T.; Mathijs, E.; Maye, D.; De Roest, K.; et al. Are local food chains more sustainable than global food chains? Considerations for assessment. Sustainability 2016, 8, 449. [CrossRef]

46. Arcese, G.; Flammini, S.; Lucchetti, M.C.; Martucci, O. Evidence and experience of open sustainability innovation practices in the food sector. Sustainability 2015, 7, 8067-8090. [CrossRef]

47. Yuan, H.; Lau, R.Y.; Xu, W. The determinants of crowdfunding success: A semantic text analytics approach. Decis. Support Syst. 2016, 91, 67-76. [CrossRef]

48. Solnik, B.; Zuo, L. Relative optimism and the home bias puzzle. Rev. Finance 2016, 21, 2045-2074. [CrossRef]

49. Lytras, M.D.; Raghavan, V.; Damiani, E. Big data and data analytics research: From metaphors to value space for collective wisdom in human decision making and smart machines. Int. J. Semant. Web Inf. Syst. 2017, 13, 1-10. [CrossRef]

50. Kwabi, F.O.; Thapa, C.; Paudyal, K.; Adegbite, E. Biases in international portfolio allocation and investor protection standards. Int. Rev. Finance Anal. 2017, 53, 66-79. [CrossRef]

51. Beugelsdijk, S.; Frijns, B. A cultural explanation of the foreign bias in international asset allocation. J. Bank. Finance 2010, 34, 2121-2131. [CrossRef]

52. Dollani, A.; Lerario, A.; Maiellaro, N. Sustaining cultural and natural heritage in Albania. Sustainability 2016, 8, 792. [CrossRef]

(C) 2018 by the authors. Licensee MDPI, Basel, Switzerland. This article is an open access article distributed under the terms and conditions of the Creative Commons Attribution (CC BY) license (http:/ / creativecommons.org/licenses/by/4.0/). 